Board of Governors of the Federal Reserve System

International Finance Discussion Papers

Number 672

July 2000

\title{
THE EQUIVALENCE OF WAGE AND PRICE STAGGERING IN MONETARY BUSINESS CYCLE MODELS
}

\author{
Rochelle M. Edge
}

NOTE: International Finance Discussion Papers are preliminary materials circulated to stimulate discussion and critical comment. References in publications to International Finance Discussion Papers (other than an acknowledgment that the writer has had access to unpublished material) should be cleared with the author or authors. Recent IFDPs are available on the Web at www.bog.frb.fed.us. 


\title{
THE EQUIVALENCE OF WAGE AND PRICE STAGGERING IN MONETARY BUSINESS CYCLE MODELS
}

\author{
Rochelle M. Edge*
}

\begin{abstract}
Chari, Kehoe, and McGratten's (1998) finding that a standard monetary business cycle model with staggered price setting is unable to generate sufficiently persistent real effects of monetary shocks has engendered a growing literature aimed at developing alternative mechanisms for producing greater persistence. The most popular approach at present in this literature appears to be one in which staggered wage contracts are used as either an alternative or a complement to a staggered price mechanism. This is informed by recent research by Andersen (1998) and Huang and Liu (1998) which finds that the staggered wage model, despite its superficial similarity to the staggered price setup, incorporates a very different microstructure that implies substantially more real persistence. This paper argues that these authors' findings rely heavily on the assumption that identical inputs are used by all firms, and demonstrates that, by assuming firm-specific factor inputs the staggered price model is as capable as the staggered wage model of generating persistent real responses to monetary shocks.
\end{abstract}

Keywords: Taylor contracting, output persistence, sticky prices, sticky wages, firm-specific factor inputs.

* Mailstop 23, Federal Reserve Board, Washington DC 20551, (202) 452 2339; FAX: (202) 736-5638; rochelle.m.edge@frb.gov. I thank Michael Woodford for his advice and helpful conversations as well as Ben Bernanke, Jonathan Parker, Jeremy Rudd, Robert Shimer, Chris Sims, and Peter Storgaard for comments on earlier drafts. All errors are my own. After completing a previous draft of this paper, I became aware of Ascari and Garcia's independently written 1999 paper, which makes several similar points. The views in this paper are solely the responsibility of the author and should not be interpreted as reflecting the views of the Board of Governors of the Federal Reserve System or of any other person associated with the Federal Reserve System. 
Chari, Kehoe, and McGratten's (1998) finding that a standard monetary business cycle model with Taylor (1980) staggered price setting is unable to generate sufficiently persistent real effects of monetary shocks has engendered a growing literature aimed at developing alternative mechanisms for producing greater persistence. Examples include Bergin and Feenstra (2000), who combine a staggered price mechanism with a non-CES production function and factor specificity, and Kiley (1997), who obtains more persistent real responses to monetary shocks by emphasizing compositional changes in output over the business cycle. However, the most popular approach in this literature appears to be one in which staggered wage contracts are used as either an alternative or a complement to a staggered price mechanism (for example, Erceg (1997), Andersen (1998), and Huang and Liu (1998)).

Proponents of the staggered wage approach argue that despite its superficial similarity to a staggered price setup, the staggered wage model incorporates a very different microstructure and, as a result, yields very different responses to monetary policy shocks (especially for plausible parameter values). Huang and Liu (1998) present a model for which staggered wages always produce monotone-damped responses for the model's real variables (that is, persistence) while staggered prices necessarily produce damped oscillations (that is, no persistence). In a similar spirit, Andersen (1998) presents a model for which staggered wages always produce responses for the model's real variables that are substantially more persistent than those implied by staggered prices. This leads these authors to favor the use of staggered wages in monetary business cycle models - as was initially proposed by Taylor (1980) — rather than staggered pricing, which was later suggested by Blanchard (1986) as an equivalent approach.

Kimball (1995), however, has noted that the use of staggered wages to generate persistent real responses to monetary shocks carries a number of unattractive implications. Wage stickiness, for example, results in countercyclical movements in the real wage, which contradicts what is observed empirically. This problem, however, can be rectified by assuming both price and wage stickiness. A more serious, less easily remedied problem comes from the fact that it is not sticky wages that are required to yield real and persistent responses to monetary policy but rather sticky labor costs, which are very difficult to justify given that within a single period, wages may not reflect true labor costs. ${ }^{1}$ These problems are less important with an assumption of sticky prices, thus, if it were possible to generate persistent real responses from a model with staggered prices, such a mechanism would certainly be preferable over an approach using staggered wages.

This paper argues that the conclusions of Andersen (1998) and Huang and Liu (1998)

\footnotetext{
${ }^{1}$ Arguably, employment takes place in a context of long-term implicit contracts in which the wage observed at any given time is only an installment payment on what the implicit contract says is due to the worker. True marginal labor costs also include additional compensation that the firm implicitly promises to pay the worker at some future date for working an extra hour. As a result, the observed wage in any period does not accurately represent the firm's labor costs in that period.
} 
regarding the relative ability of price and wage staggering to generate persistent responses to monetary shocks rely heavily on their assumptions concerning factor markets: specifically, that identical sets of inputs are used by all firms. The paper demonstrates that, by assuming firm-specific factor inputs - a mechanism that has been suggested by Kimball (1995) and Rotemberg (1996) as a means of generating increased real persistence - the staggered price model is capable of generating responses of real variables to monetary shocks that display the same degree of persistence as those emerging from the staggered wage model. The paper thus concludes that monetary business cycle modelers need not rely on wage staggering to generate real persistence in their models; the assumption of sticky prices (which is more easily justified than the assumption of sticky labor costs) is equally effective in generating desirable and intuitive responses to monetary shocks.

I begin by presenting a very simplified, stripped-down model; this allows me to obtain analytical solutions that I can use to demonstrate the similarity of the microstructures that underlie wage and price staggering. In this model, the responses to monetary shocks under staggered prices are essentially identical to those emerging under staggered wages. Next, I present a more detailed version of the model (incorporating additional intertemporal links and more realistically specified equations) that I use to generate impulse responses to monetary shocks. The analytical results are largely robust to the richer specification of the model; the responses of real output (and its components) that obtain from the staggered price and staggered wage models are again essentially equivalent. As might be expected from the previous discussion, the assumption as to whether the assumed price stickiness is located in the model's factor or product market has a considerable influence on the resulting responses of inflation and real wages. Most notably, while the staggered pricing mechanism results in procyclical movements in the real wage, the assumption of staggered wages generates countercyclical movements for some parameter values.

\section{Wage Staggering in a Simple Monetary Business Cycle Model}

\subsection{The Model}

The model presented in this section follows closely the simplified staggered wage monetary business cycle model of Andersen (1998) and Huang and Liu (1998). The economy is assumed to be characterized by the following set of agents: a continuum of households distributed over the unit interval, each of which consumes the economy's output and acts as a monopolistically competitive supplier of a differentiated labor input; a representative firm, which hires all of the specific labor inputs to produce the economy's output; and a monetary authority, whose policy rule yields an evolution equation for nominal output of: 


$$
P_{t} Y_{t}=P_{t-1} Y_{t-1} \exp \left[\varepsilon_{t}\right]
$$

where $Y_{t}$ and $P_{t}$ denote the economy's real output and price level in period $t$ and $\varepsilon_{t}$ represents the nominal shock to the economy. ${ }^{2}$

The economy's market-clearing condition implies that:

$$
C_{t}=Y_{t}
$$

where $C_{t}$ denotes aggregate consumption.

\subsubsection{The Firm's Problem}

The firm's production function is given by:

$$
Y_{t}=\left(\int_{0}^{1}\left(H_{t}^{i}\right)^{\frac{\sigma-1}{\sigma}} d i\right)^{\frac{\sigma}{\sigma-1}}
$$

where $H_{t}^{i}$ denotes the firm's use of the labor input of the $i$ th household and $\sigma$ represents the elasticity of substitution across inputs. The firm takes the wages set by households for their differentiated labor input as given, and solves the following cost-minimization problem:

$$
\min \int_{0}^{1} \omega_{t}^{i} H_{t}^{i} d i \text { subject to } Y_{t} \leq\left(\int_{0}^{1}\left(H_{t}^{i}\right)^{\frac{\sigma-1}{\sigma}} d i\right)^{\frac{\sigma}{\sigma-1}}
$$

where $\omega_{t}^{i}$ is the wage rate for $H_{t}^{i}$. This yields labor demand curves that are given by:

$$
H_{t}^{i}=Y_{t} \cdot\left(\frac{\omega_{t}^{i}}{P_{t}}\right)^{-\sigma}
$$

The firm sets the price of its output competitively (that is, equal to its marginal cost, $M C_{t}$ ), so that:

$$
P_{t}=M C_{t}=\left(\int_{0}^{1}\left(\omega_{t}^{i}\right)^{1-\sigma} d i\right)^{\frac{1}{1-\sigma}}
$$

\footnotetext{
${ }^{2}$ In essence, this assumes that the monetary authority follows a nominal GDP targeting rule, which is in turn identical to assuming, as is frequently done in this literature, that money demand obeys the quantity theory of money (with the velocity of circulation held constant) and that the policy shock represents a one-time increase in the economy's nominal money supply.
} 


\subsubsection{The Households' Problem}

As noted above, the household sector of the economy is composed of a continuum of infinitely lived representative households. The preferences of household $i$ are represented by the utility function:

$$
U_{0}^{i}=E_{0}\left\{\sum_{t=0}^{\infty} \beta^{t}\left[U\left(C_{t}^{i}\right)-V\left(H_{t}^{i}\right)\right]\right\}
$$

where $C_{t}^{i}$ is household $i$ 's consumption of the economy's single good, $H_{t}^{i}$ is its supply of its differentiated labor services, and the parameter $\beta$ denotes the households' common discount factor. Huang and Liu (1998) define $U\left(C_{t}^{i}\right)=\ln \left(C_{t}^{i}\right)$, while Andersen (1998) implicitly defines $U\left(C_{t}^{i}\right)$ to be linear. I make no assumption here as to the functional form of $U\left(C_{t}^{i}\right)$ (except for the usual derivative conditions), and assume that $V^{\prime}\left(H_{t}^{i}\right) \geq 0$ and $V^{\prime \prime}\left(H_{t}^{i}\right) \geq 0$.

Household $i$ 's flow budget constraint is given by:

$$
B_{t}^{i} \leq R_{t-1} B_{t-1}^{i}+\omega_{t}^{i} H_{t}^{i}-T_{t}^{i}-P_{t} C_{t}^{i},
$$

where $B_{t}^{i}$ denotes household $i$ 's end-of-period $t$ holdings of nominal bonds, $R_{t}$ is the gross nominal interest rate, $\omega_{t}^{i}$ is the nominal wage rate for household $i$ 's differentiated labor service, and $T_{t}^{i}$ denotes net taxes paid by household $i$.

Household $i$ chooses $\left\{C_{t}^{i}, \omega_{t}^{i}\right\}_{t=0}^{\infty}$ to maximize its utility (equation (6)) subject to its budget constraint (equation (7)) and the demand for its differentiated labor service (equation (4)). The utility-maximization problem yields the following Euler equation for household consumption:

$$
\left(\frac{U^{\prime}\left(C_{t}^{i}\right)}{P_{t}}\right)=R_{t} \beta E_{t}\left[\left(\frac{U^{\prime}\left(C_{t+1}^{i}\right)}{P_{t+1}}\right)\right] .
$$

I assume two-period Taylor (1980) wage staggering; specifically, households indexed by $i \in\left[0, \frac{1}{2}\right]$ set new wages in periods $\{t+2 k\}_{k=0}^{\infty}$, while those indexed by $i \in\left(\frac{1}{2}, 1\right]$ set new wages in periods $\{t+2 k+1\}_{k=0}^{\infty}$. Thus, for household $i$ with $i \in\left[0, \frac{1}{2}\right]$, the first-order condition for wages is given by: $:^{3}$

$$
\widetilde{\omega}_{t}=\left(\frac{\sigma}{\sigma-1}\right) E_{t}\left[\frac{Y_{t} V^{\prime}\left(Y_{t}\left(\widetilde{\omega}_{t}\right)^{-\sigma}\right)+\beta Y_{t+1}\left(\frac{1}{\Pi_{t+1}}\right)^{-\sigma} V^{\prime}\left(Y_{t+1}\left(\frac{\widetilde{\omega}_{t}}{\Pi_{t+1}}\right)^{-\sigma}\right)}{Y_{t} U^{\prime}\left(C_{t}^{i}\right)+\beta Y_{t+1}\left(\frac{1}{\Pi_{t+1}}\right)^{1-\sigma} U^{\prime}\left(C_{t+1}^{i}\right)}\right]
$$

where $\widetilde{\omega}_{t}$ denotes the ratio of wages set this period to the aggregate wage level (which in this case equals the aggregate price level), while $\Pi_{t}$ denotes the (gross) inflation rate $\frac{P_{t}}{P_{t-1}}$.

\footnotetext{
${ }^{3}$ In what follows, a tilde over a variable distinguishes the variable's real value from its nominal counterpart.
} 
Since households receive different wages and work different hours depending on whether they are members of $\left[0, \frac{1}{2}\right]$ or $\left(\frac{1}{2}, 1\right]$ (even though within their subinterval $\left[0, \frac{1}{2}\right]$ or $\left(\frac{1}{2}, 1\right]$ they are identical), their accumulated wealth and consumption profiles are likely to differ. To simplify the problem and allow a single consumption profile to characterize all households, I assume that asset portfolios can be constructed so as to provide the household with complete insurance against any idiosyncratic risk. Consequently, a household's wealth is independent of the period in which it sets its wage. Since $C_{t}=\int_{0}^{1} C_{t}^{i} d i$, this assumption allows the $i$ superscripts to be dropped from equation (8). This assumption is used repeatedly throughout the paper in situations where different households receive different labor incomes.

\subsection{Log-linearizing and Solving the Model}

As is standard, a solution is obtained by log-linearizing the behavioral equations around a steady-state equilibrium. ${ }^{4}$ The important log-linearized equations are those for the households' labor supply decision, the evolution of the inflation rate, and the evolution of nominal output. ${ }^{5}$ Using the substitutions allowed by equations (2) and (5), these FOCs become:

$$
\begin{gathered}
\widehat{\widetilde{w}}_{t}=\gamma\left(\frac{1}{1+\beta} \widehat{Y}_{t}+\frac{\beta}{1+\beta} E_{t} \widehat{Y}_{t+1}\right)+\frac{\beta}{1+\beta} E_{t} \widehat{\Pi}_{t+1} \\
\widehat{\Pi}_{t}=\widehat{\widetilde{\omega}}_{t}+\widehat{\widetilde{\omega}}_{t-1}, \text { and } \\
\varepsilon_{t}=\widehat{Y}_{t}-\widehat{Y}_{t-1}+\widehat{\Pi}_{t}
\end{gathered}
$$

The parameter $\gamma$, which has the interpretation of the elasticity of wages with respect to output, is equal to $\frac{\rho_{h h}-\rho_{c c}}{1+\sigma \rho_{h h}}$, where $\rho_{c c}$ and $\rho_{h h}$ are the elasticities of intertemporal consumption and labor substitution. ${ }^{6}$ Further manipulations yield the following system of linear difference equations:

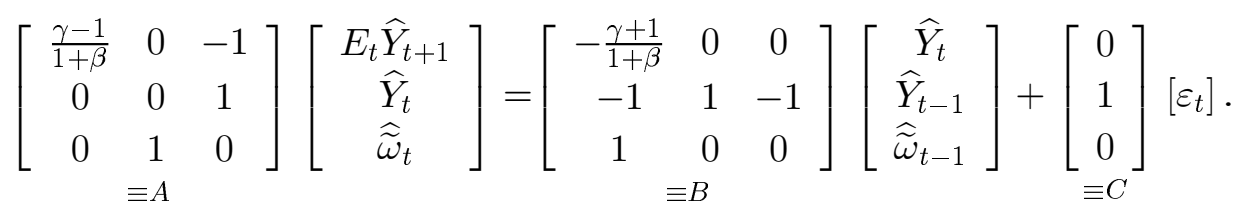

\footnotetext{
${ }^{4}$ Equilibrium is an allocation $\left\{C_{t}, \frac{M_{t}}{P_{t}}, H_{t}, Y_{t}\right\}_{t=0}^{\infty}$ and a sequence of prices $\left\{\Pi_{t+1}, \widetilde{\omega}_{t}, R_{t}, \widetilde{M C}_{t}\right\}_{t=0}^{\infty}$ that satisfy equations (1) to $(5)$ and (8) to (9), given the sequence of monetary policy shocks $\left\{\varepsilon_{t}\right\}_{t=0}^{\infty}$. The variables that constitute the equilibrium have been defined so as to ensure that their steady-state values remain constant over time.

${ }^{5}$ In what follows, a caret over a variable denotes its percentage deviation from its steady-state value.

${ }^{6}$ Huang and Liu's (1998) model implies $\rho_{c c}=-1$, while Andersen's (1998) model implies $\rho_{c c}=0$.
} 
As Blanchard and Kahn (1980) have shown, a unique stationary equilibrium exists when the number of stable eigenvalues of the matrix $A^{-1} B$ is equal to the number of predetermined variables in the system, which in this case is two. By solving the system analytically, it can be shown that a unique stationary equilibrium will exist for plausible values of $\beta$ and $\gamma$ (that is, values of $\beta$ close to 1 and values of $\gamma$ greater than zero).

Chari, Kehoe, and McGratten (1998), and Huang and Liu (1998), using the simplification that $\beta=1$, show that $\widehat{Y}_{t}$ evolves according to:

$$
\widehat{Y}_{t}=a \widehat{Y}_{t-1}+b \varepsilon_{t}
$$

where

$$
a=\frac{1-\sqrt{\gamma}}{1+\sqrt{\gamma}}
$$

and $b$ is some positive coefficient. Clearly, for $\gamma<1,0<a<1$ (that is, we observe monotone-damped responses-persistence) and for $\gamma>1,-1<a<0$ (that is, we observe damped oscillations - no persistence). In the case of wage staggering, with $\sigma>1$ and $\rho_{h h}>0, \gamma$ will be less that one when $\rho_{c c}$ falls in the interval $[-1,0]$, which includes the values for $\rho_{c c}$ assumed by Andersen (1998) and Huang and Liu (1998). Thus, as claimed by Andersen (1998) and Huang and Liu (1998), wage staggering necessarily leads to persistent real responses to monetary shocks.

\section{Price Staggering in a Simple Monetary Business Cycle Model}

I now consider a similar model with price staggering. The objective is to show that a staggered price monetary business cycle model with homogeneous factor inputs is unable to generate persistent real responses to nominal shocks whereas the same model with firmspecific factor inputs is capable of doing so. The model presented in the first two parts of this section follows closely the simplified staggered price monetary business cycle model of Andersen (1998) and Huang and Liu (1998).

\subsection{The Model with a Homogeneous Labor Input}

The simplified economy is characterized by the following set of agents: a continuum of households, distributed over the unit interval, who consume each of the differentiated outputs and atomistically supply a homogeneous labor input; a continuum of monopolistically competitive firms, also distributed over the unit interval, each of which hires the homogeneous labor input to produce its variety of the differentiated output (meeting demand at some posted price); and a monetary authority that follows a monetary policy rule that 
yields an evolution equation for nominal output in the form of equation (1). As before, market clearing is given by equation (2).

\subsubsection{The Households' Problem}

The households' problem is similar to before except that now households consume each of the economy's differentiated outputs. Household $i$ 's aggregate consumption, $C_{t}^{i}$, is defined as:

$$
C_{t}^{i}=\left(\int_{0}^{1}\left(C_{t}^{i, j}\right)^{\frac{\theta-1}{\theta}} d j\right)^{\frac{\theta}{\theta-1}}
$$

where $C_{t}^{i, j}$ is $i$ 's consumption of firm $j$ 's output and $\theta$ is the elasticity of substitution between each of the differentiated outputs. Given the prices set by firms for their differentiated outputs, household $i$ solves the following expenditure-minimization problem:

$$
\min \int_{0}^{1} p_{t}^{j} C_{t}^{i, j} d j \text { subject to } C_{t}^{i} \leq\left(\int_{0}^{1}\left(C_{t}^{i, j}\right)^{\frac{\theta-1}{\theta}} d j\right)^{\frac{\theta}{\theta-1}}
$$

where $p_{t}^{j}$ is the price of firm $j$ 's output and $C_{t}^{i}$ satisfies the Euler equation given by (8). The expenditure-minimization problem yields household $i$ 's demand for the $j$ th good:

$$
C_{t}^{i, j}=C_{t}^{i} \cdot\left(\frac{p_{t}^{j}}{P_{t}}\right)^{-\theta}
$$

where the price index for aggregate consumption is given by:

$$
P_{t}=\left(\int_{0}^{1}\left(P_{t}^{j}\right)^{1-\theta} d j\right)^{\frac{1}{1-\theta}}
$$

Although household $i$ 's first-order condition for consumption is the same as before, the first-order condition for hours supplied changes since wages are now fully flexible and households no longer have market power over their labor. Specifically, the first-order condition for hours supplied becomes:

$$
\frac{\omega_{t}^{i}}{P_{t}}=\frac{V^{\prime}\left(H_{t}^{i}\right)}{U^{\prime}\left(C_{t}^{i}\right)}
$$

Since all households receive the same real wage, $\left\{\left\{C_{t+s}^{i, j}\right\}_{j=0}^{1}, C_{t+s}^{i}, H_{t+s}^{i}\right\}_{s=0}^{\infty}$ will be identical across households. As a result, the households' first-order conditions (13), (8), and (15) can be written without the $i$ superscripts. 


\subsubsection{The Firms' Problem}

The monopolistically competitive firm $j$ acts as a price-taker in hiring the homogeneous labor input and produces its differentiated good according to the production function

$$
Y_{t}^{j}=H_{t}^{j}-F C
$$

where $F C$, which represents the fixed cost faced by the firm, is set so as to leave the firm with no monopoly rents in the long run. As before, this production function implies that the marginal cost facing the firm is equal to the wage of the homogeneous input (that is, $\left.M C_{t}^{j}=\omega_{t}\right)$.

Two-period staggered price setting is described in the same way that wage staggering was modeled above; specifically, firms indexed by $j \in\left[0, \frac{1}{2}\right]$ set new wages in periods $\{t+2 k\}_{k=0}^{\infty}$, while those indexed by $j \in\left(\frac{1}{2}, 1\right]$ set new wages in periods $\{t+2 k+1\}_{k=0}^{\infty}$. Thus, the first-order condition for prices for firm $j$ where $j \in\left[0, \frac{1}{2}\right]$ is given by:

$$
\widetilde{x}_{t}=\left(\frac{\theta}{\theta-1}\right) E_{t}\left[\frac{Y_{t} \widetilde{M C}_{t}^{j}+\left(\frac{\Pi_{t+1}}{R_{t}}\right) Y_{t+1} \widetilde{M C}_{t+1}^{j}\left(\frac{1}{\Pi_{t+1}}\right)^{-\theta}}{Y_{t}+\left(\frac{1}{R_{t}}\right) Y_{t+1}\left(\frac{1}{\Pi_{t+1}}\right)^{-\theta}}\right] \text {, }
$$

where $\widetilde{x}_{t}$ denotes the ratio of prices set this period to the aggregate price level and $\widetilde{M C}_{t}^{j}$ denotes the real marginal cost of production for firm $j$ in period $t$. A number of simple substitutions yields the following expression for marginal cost:

$$
\begin{aligned}
\widetilde{M C}_{t}^{j} & =\frac{\omega_{t}}{P_{t}}=\frac{V^{\prime}\left(H_{t}\right)}{U^{\prime}\left(C_{t}\right)}=\frac{V^{\prime}\left(\int_{0}^{1} H_{t}^{j} d j\right)}{U^{\prime}\left(C_{t}\right)}=\frac{1}{U^{\prime}\left(Y_{t}\right)} V^{\prime}\left(\int_{0}^{1}\left(Y_{t}^{j}+F C\right) d j\right) \\
& =\frac{1}{U^{\prime}\left(Y_{t}\right)} V^{\prime}\left(\frac{1}{2} Y_{t}\left(\left(\widetilde{x}_{t}\right)^{-\theta}+\left(\frac{\widetilde{x}_{t-1}}{\Pi_{t}}\right)^{-\theta}\right)+F C\right)=\frac{1}{U^{\prime}\left(Y_{t}\right)} V^{\prime}\left(Y_{t}+F C\right)
\end{aligned}
$$

It is apparent from the above equation that because all firms use the same homogeneous labor input, they all face the same marginal cost of production and will therefore all set the same new price. As a result, the price-setting equation (16) can be written without the $j$ superscripts. Finally, substituting for marginal cost in equation (16) yields:

$$
\tilde{x}_{t}=\left(\frac{\theta}{\theta-1}\right) E_{t}\left[\frac{\frac{Y_{t}}{U^{\prime}\left(Y_{t}\right)} V^{\prime}\left(Y_{t}+F C\right)+\left(\frac{\Pi_{t+1}}{R_{t}}\right) \frac{Y_{t+1}}{U^{\prime}\left(Y_{t+1}\right)} V^{\prime}\left(Y_{t+1}+F C\right)\left(\frac{1}{\Pi_{t+1}}\right)^{-\theta}}{Y_{t}+\left(\frac{1}{R_{t}}\right) Y_{t+1}\left(\frac{1}{\Pi_{t+1}}\right)^{-\theta}}\right] .
$$




\subsection{Log-linearizing and Solving the Model}

The first-order conditions are log-linearized around the steady-state equilibrium. ${ }^{7}$ Linearizing equation (17) gives:

$$
\widehat{\widetilde{x}}_{t}=\gamma\left(\frac{1}{1+\beta} \widehat{Y}_{t}+\frac{\beta}{1+\beta} E_{t} \widehat{Y}_{t+1}\right)+\frac{\beta}{1+\beta} E_{t} \widehat{\Pi}_{t+1}
$$

where $\gamma$, which now equals $\left(\rho_{h h}\left(\frac{\theta-1}{\theta}\right)-\rho_{c c}\right)$, denotes the elasticity of prices with respect to output. The other important log-linearized equations are those that give the evolution of the inflation rate and of nominal output:

$$
\begin{gathered}
\widehat{\Pi}_{t}=\widehat{\widetilde{x}}_{t}+\widehat{\widetilde{x}}_{t-1} \text { and } \\
\varepsilon_{t}=\widehat{Y}_{t}-\widehat{Y}_{t-1}+\widehat{\Pi}_{t} .
\end{gathered}
$$

The structure of this system of stochastic linear difference equations is identical to that presented in section 1.2. As in section 1.2 we could write the system of linear difference equations in matrix form; doing this would give us the same set of matrices $A, B$, and $C$, while the vector of model variables would change slightly to $\left[\begin{array}{lll}\widehat{Y}_{t}, & \widehat{Y}_{t-1}, & \widehat{\widetilde{x}}_{t-1}\end{array}\right]^{\prime}$. A unique stationary equilibrium exists for all plausible values of $\gamma$ and $\widehat{Y}_{t}$ evolves over time according to equation (11).

As before, the key to whether we have persistent real effects of nominal shocks lies in the value of $\gamma$ relative to unity. However, the value of $\gamma$ is different for the staggered price model. In Huang and Liu's (1998) model with $\rho_{c c}=-1, \rho_{h h}>0$, and $\theta>1$, the parameter $\gamma$ is necessarily greater than one, which implies dampened oscillations (that is, no persistence). While it is possible in Andersen's (1998) model with $\rho_{c c}=0$ to generate real persistence (that is $\gamma<1$ ) by assuming $\rho_{h h}<\left(\frac{\theta}{\theta-1}\right)$, the resulting value of $\gamma$ is necessarily higher than the value of $\gamma$ from the staggered wage model, (and therefore implies less persistence under price staggering than under wage staggering).

It is this set of findings that leads Erceg (1997), Andersen (1998), and Huang and Liu (1998) to favor wage staggering over price staggering as a way to bring real persistence into a monetary business cycle model. The following two sections, however, show that these authors' results depend heavily on the assumption of a homogeneous labor input and are changed substantially when firm-specific labor inputs are assumed.

\footnotetext{
${ }^{7}$ Equilibrium is an allocation $\left\{\left\{C_{t}^{j}\right\}_{j=0}^{1}, C_{t}, \frac{M_{t}}{P_{t}}, H_{t}, Y_{t}\right\}_{t=0}^{\infty}$ and $\quad$ a sequence of prices $\left\{\Pi_{t+1}, \frac{\omega_{t}}{P_{t}}, \widetilde{x}_{t}, R_{t}, \widetilde{M C}_{t}\right\}_{t=0}^{\infty}$ that satisfy equations (1) to (5), (8), (13) to (15), and (17), given the sequence of monetary shocks $\left\{\varepsilon_{t}\right\}_{t=0}^{\infty}$.
} 


\subsection{The Model with Firm-Specific Labor Inputs}

The simple model with firm-specific labor inputs is very similar to the model presented above. However, while the preceding model assumed that each household and firm sold or bought its labor in a general homogeneous market, I now assume that each household along the unit interval is coupled with a firm along the unit interval and is restricted to sell its labor to that firm only. For simplicity, I assume that household $i$ sells its labor to firm $j$ where $i=j$.

For households, the first-order conditions are still equations (13), (8), and (15). ${ }^{8}$ Since I again assume that asset portfolios can be constructed to keep all households' wealth stocks (and hence consumption profiles) equal, equations (13) and (8) can be written without the $i$ subscripts.

For firms, the key difference is that marginal cost now depends on the wage paid to the firm-specific labor input:

$$
\begin{aligned}
\widetilde{M C}_{t}^{j} & =\frac{\omega_{t}^{j}}{P_{t}}=\frac{\omega_{t}^{i}}{P_{t}}=\frac{V^{\prime}\left(H_{t}^{i}\right)}{U^{\prime}\left(C_{t}^{i}\right)}=\frac{V^{\prime}\left(H_{t}^{j}\right)}{U^{\prime}\left(C_{t}\right)} \\
& =\frac{V^{\prime}\left(Y_{t}^{j}+F C\right)}{U^{\prime}\left(Y_{t}\right)}=\frac{V^{\prime}\left(Y_{t}\left(\widetilde{x}_{t}\right)^{-\theta}+F C\right)}{U^{\prime}\left(Y_{t}\right)}
\end{aligned}
$$

where the fact that $i=j$ allows us to write $\omega_{t}^{j}=\omega_{t}^{i}$ and $H_{t}^{j}=H_{t}^{i}$. Firms, however, are still assumed to act as price takers in their relevant factor markets, so the first-order condition for prices is given by equation (16). ${ }^{9}$ Substituting this expression for marginal cost into equation (16) yields:

$$
\begin{aligned}
\widetilde{x}_{t}= & \left(\frac{\theta}{\theta-1}\right) E_{t}\left[\frac{\frac{Y_{t}}{U^{\prime}\left(Y_{t}\right)} V^{\prime}\left(Y_{t}\left(\widetilde{x}_{t}\right)^{-\theta}+F C\right)}{Y_{t}+\left(\frac{1}{R_{t}}\right) Y_{t+1}\left(\frac{1}{\Pi_{t+1}}\right)^{-\theta}}\right] \\
& +\left(\frac{\theta}{\theta-1}\right) E_{t}\left[\frac{\left(\frac{\Pi_{t+1}}{R_{t}}\right) \frac{Y_{t+1}}{U^{\prime}\left(Y_{t+1}\right)} V^{\prime}\left(Y_{t+1}\left(\frac{\widetilde{x}_{t}}{\Pi_{t+1}}\right)^{-\theta}+F C\right)\left(\frac{1}{\Pi_{t+1}}\right)^{-\theta}}{Y_{t}+\left(\frac{1}{R_{t}}\right) Y_{t+1}\left(\frac{1}{\Pi_{t+1}}\right)^{-\theta}}\right],
\end{aligned}
$$

while linearizing around equilibrium ${ }^{10}$ gives:

\footnotetext{
${ }^{8} \mathrm{I}$ assume that even though a household supplies firm-specific labor it has no monopoly power over its labor. Similarly, the firm that purchases the household's labor is assumed to have no monopsony power.

${ }^{9}$ One way to (informally) motivate this is to think of each point on the continuum as identifying a single factor market whose participants include a large (though finite) number of identical households and firms (more concretely, we could think of this as a region, city, or industry).

${ }^{10}$ Equilibrium is an allocation $\left\{\left\{C_{t}^{j}\right\}_{j=0}^{1}, C_{t}, \frac{M_{t}}{P_{t}},\left\{H_{t}^{i}\right\}_{i=0}^{1}, Y_{t}\right\}_{t=0}^{\infty}$ and a sequence of prices
} 


$$
\widehat{\widetilde{x}}_{t}=\gamma\left(\frac{1}{1+\beta} \widehat{Y}_{t}+\frac{\beta}{1+\beta} E_{t} \widehat{Y}_{t+1}\right)+\frac{\beta}{1+\beta} E_{t} \widehat{\Pi}_{t+1}
$$

where $\gamma$ equals $\left(\frac{\rho_{h h}\left(\frac{\theta-1}{\theta}\right)-\rho_{c c}}{1+\rho_{h h}(\theta-1)}\right)$. The structure of the system of linear difference equations implied by factor-specific labor inputs is the same as in the case of a homogeneous labor input since the two other equations in the system remain unchanged. Once again, the only difference between the two systems lies with the parameter $\gamma$. With firm-specific labor, $\gamma<1$, and so a model with staggered prices and firm-specific labor inputs necessarily yields a monotone-damped impulse response for output - that is, persistence.

\section{Discussion of the Analytical Results}

The analysis of the previous section finds that a staggered price monetary business cycle model with firm-specific labor inputs can yield persistent real effects of nominal shocks. This result demonstrates the claim that the conclusions of Andersen (1998) and Huang and Liu (1998) rely greatly on their assumptions concerning factor markets.

To understand why the staggered wage model and the staggered price model with firmspecific labor can produce persistent real responses to monetary policy while the staggered price model with homogeneous labor cannot, it is useful to examine the three models' wage- and price-setting equations (equations (9), (17), and (18)). It is apparent from these equations that the models that yield persistent real responses to nominal shocks involve some feedback effect that arises when prices or wages are reset. Real persistence obtains because these additional effects induce wage- or price-setters to change their prices more modestly, thus allowing a given nominal shock to have longer-lasting real effects. To see exactly how these effects result in smaller price changes, I trace through the impact of a one-time increase in nominal output in each of the models.

In the staggered wage model an increase in nominal output leads to an increase in real output, which in turn increases consumption and the amount of differentiated labor input that each household supplies. Since this leads to a $\rho_{c c}$ proportional decline in the marginal utility of consumption and a $\rho_{h h}$ proportional increase in the marginal disutility of working, one would expect a $\left(\rho_{h h}-\rho_{c c}\right)$ proportional upward adjustment of the household's posted wage when its wage resetting opportunity arises. An increase in the wage will, however, reduce the demand for the household's differentiated labor services by a factor $\sigma$. This reduces the initial increase in hours supplied and disutility of labor proportionally by $\rho_{h h}$,

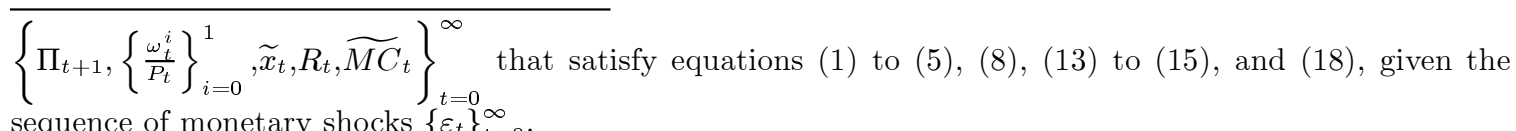


but has only a second-order effect on consumption. The household therefore scales down its desired wage increase of $\left(\rho_{h h}-\rho_{c c}\right)$ by an amount $\left(1+\sigma \rho_{h h}\right)$.

A similar outcome emerges from the staggered-price model with differentiated labor inputs. The increase in nominal output boosts real output and consumption (both in the aggregate and for each differentiated good), which raises each firm's demand for its specific labor input. Increased aggregate consumption and increased hours supplied raise the real wage by a factor $\left(\left(\frac{\theta-1}{\theta}\right) \rho_{h h}-\rho_{c c}\right)$ for reasons that are similar to those outlined above. This increases firms' marginal costs, which motivates them to increase their price when the relevant period comes around. However, an increase in price reduces demand for the firm's differentiated good by a factor $\theta$, causing reduced demand for its specific labor input which in turn lowers its wage and marginal cost by a factor $\left(\frac{\theta-1}{\theta}\right) \rho_{h h}$. The proportional increase of $\left(\left(\frac{\theta-1}{\theta}\right) \rho_{h h}-\rho_{c c}\right)$ is thus scaled down by a factor $\left(1+(\theta-1) \rho_{h h}\right)$, implying a more modest increase in prices.

The chain of events that characterizes the two previous models does not, however, obtain in the staggered price model with a homogeneous labor input. As in the previous models, the increase in nominal output raises real output and consumption of each differentiated good, which forces up the aggregate real wage and each firm's marginal cost by a factor $\left(\left(\frac{\theta-1}{\theta}\right) \rho_{h h}-\rho_{c c}\right)$. When the relevant period arises, the increase in marginal cost prompts the firm to raise its price. In this case, however, there are essentially no feedback effects from the price increase on marginal cost and thus no force to attenuate the initial rise in prices. A proportional increase in prices equal to $\left(\left(\frac{\theta-1}{\theta}\right) \rho_{h h}-\rho_{c c}\right)$ results, which is greater than the increase from the previous model. ${ }^{11}$

\footnotetext{
${ }^{11}$ It is worth noting how Chari, Kehoe and McGratten's (1998) approach to Kimball's (1995) and Rotemberg's (1996) suggestion of firm-specific inputs corresponds to the above discussion.

Chari, Kehoe and McGratten (1998) assume that firms face a production function of:

$$
Y_{t}^{j}=\left(H_{t}^{j}\right)^{1-\psi} J^{\psi}-F C
$$

where $H_{t}^{j}$ is firm $j$ 's use of the homogeneous labor input while $J$ is firm $j$ 's fixed undepreciable firm-specific input. It is assumed that all firms are endowed with identical quantities of their firm-specific input and that each firms' firm-specific input is useful only to itself. Consequently firms face no cost on their firm-specific input. The firm's production function implies a short-run Phillips curve of:

$$
\widehat{\widetilde{x}}_{t}=\gamma\left(\frac{1}{1+\beta} \widehat{Y}_{t}+\frac{\beta}{1+\beta} E_{t} \widehat{Y}_{t+1}\right)+\frac{\beta}{1+\beta} E_{t} \widehat{\Pi}_{t+1}
$$

where $\gamma=\frac{1+\rho_{h h}\left(\frac{\theta-1}{\theta}\right)\left(\frac{1}{1-\psi}\right)+\left(\frac{\theta-1}{\theta}\right)\left(\frac{\psi}{1-\psi}\right)}{1+(\theta-1)\left(\frac{\psi}{1-\psi}\right)}$.

Thus, in this model, despite the lack of feedback of the subsequent effects on the price increase via the wage rate, there is some feedback from marginal cost increasing in output. Here, however, the firm-specific inputs do not necessarily yield persistent real responses to monetary shocks (that is, $\gamma<1$ ) but require that $\theta-\frac{\rho_{h h}}{\psi}>1$.
} 
What is interesting to note from the above discussion is that - contrary to the claims of Andersen (1998) and Huang and Liu (1998) - it is not the assumption of staggered prices that renders the model of section 2.1 unable to generate a persistent real response to a monetary shock but rather the assumption of homogeneous factor markets. Another result that contradicts the conclusions of these authors involves the similarity of the coefficient $\gamma$ in the staggered wage model, where $\gamma=\left(\frac{\rho_{h h}-\rho_{c c}}{1+\theta \rho_{h h}}\right)$, and in the staggered price model with firm-specific inputs, where $\gamma=\left(\frac{\rho_{h h}\left(\frac{\theta-1}{\theta}\right)-\rho_{c c}}{1+\rho_{h h}(\theta-1)}\right)$. The only difference between the parameter values arises not from any asymmetries between staggered wages and staggered prices but rather from the assumption that in the model with staggered wages households enjoy the rents from their monopoly power, while in the model with staggered prices firms' rents are absorbed by fixed costs that exist in the production of the intermediate good. If these asymmetries were eliminated the parameter values of $\gamma$ would be identical for both sets of models. The equivalence of the models in this regard stems from the fact that in a very simplified model with only one factor input and a linear production function, it becomes immaterial whether it is goods or factors that are being aggregated, as well as where in the process of transforming differentiated labor into aggregate consumption the monopolistic competition arises. ${ }^{12}$

\section{Consequences of an Endogenous Capital Stock}

\subsection{A Staggered Wage Model}

The more detailed version of the staggered wage model modifies the simple model of section 1 by incorporating capital as a factor of production. The functional forms that I employ closely follow those employed by Huang and Liu (1998).

The nominal shock to the economy, now a shock to the growth rate of the nominal money supply, is characterized by:

$$
\mu_{t}=\left(\mu_{t-1}\right)^{\rho} \exp \left[\varepsilon_{t}\right] \quad(0<\rho<1)
$$

while the economy's market-clearing condition is given by:

$$
I_{t}+C_{t}=Y_{t}
$$

where $I_{t}$ denotes investment in capital.

The firm now uses capital and labor in production. Output is given by:

\footnotetext{
${ }^{12}$ In the case of a concave production function Ascari and Garcia (1999) show that staggered prices deliver a higher degree of persistence than staggered wages.
} 


$$
Y_{t}=\left(\left(\int_{0}^{1}\left(H_{t}^{i}\right)^{\frac{\sigma-1}{\sigma}} d i\right)^{\frac{\sigma}{\sigma-1}}\right)^{1-\alpha} K_{t}^{\alpha}
$$

where $K_{t}$ is the economy's capital stock and $\alpha$ is the elasticity of output with respect to capital. The firm's cost-minimization problem yields the following equations for $H_{t}^{i}$ and $K_{t}$ :

$$
\begin{gathered}
H_{t}^{i}=\left(\frac{\alpha}{1-\alpha}\right)^{-\alpha} Y_{t}\left(\frac{\widetilde{\Omega}_{t}}{\widetilde{\rho}_{t}}\right)^{-\alpha}\left(\frac{\frac{\omega_{t}^{i}}{P_{t}}}{\widetilde{\Omega}_{t}}\right)^{-\sigma} \\
K_{t}=\left(\frac{\alpha}{1-\alpha}\right)^{1-\alpha} Y_{t}\left(\frac{\widetilde{\Omega}_{t}}{\widetilde{\rho}_{t}}\right)^{1-\alpha}
\end{gathered}
$$

where $\widetilde{\rho}_{t}$ is the real rental rate on the economy's capital stock and $\widetilde{\Omega}_{t}$ is a real wage index given by:

$$
\widetilde{\Omega}_{t}=\left(\int_{0}^{1}\left(\frac{\omega_{t}^{i}}{P_{t}}\right)^{1-\sigma} d i\right)^{\frac{1}{1-\sigma}}
$$

Perfect competition in the goods market implies that real marginal cost must always equal one:

$$
\widetilde{M C}=\left(\frac{\widetilde{\Omega}_{t}}{1-\alpha}\right)^{1-\alpha}\left(\frac{\widetilde{\rho}_{t}}{\alpha}\right)^{\alpha}=1
$$

The preferences of household $i$ are represented by the utility function:

$$
U_{0}^{i}=E_{0}\left\{\sum_{t=0}^{\infty} \beta^{t}\left[\ln \left(b\left(C_{t}^{i}\right)^{v}+(1-b)\left(\frac{M_{t}^{i}}{P_{t}}\right)^{v}\right)^{\frac{1}{v}}+\eta \ln \left(1-H_{t}^{i}\right)\right]\right\}
$$

where $b, \nu$ and $\eta$ are parameters. The household's flow budget constraint is:

$$
B_{t}^{i}+M_{t}^{i} \leq R_{t-1} B_{t-1}^{i}+M_{t-1}^{i}+\omega_{t}^{i} H_{t}^{i}+\rho_{t} K_{t}^{i}+\text { profits }_{t}-T_{t}^{i}-P_{t} C_{t}^{i} .
$$

Household $i$ chooses $\left\{C_{t}^{i}, M_{t}^{i}, K_{t}^{i}, \omega_{t}^{i}\right\}_{t=0}^{\infty}$ to maximize its utility subject to its budget constraint, the labor demand function specific to its differentiated labor service (equation (22)), and the evolution of its holding of the capital stock:

$$
E_{t} K_{t+1}^{i}=(1-\delta) K_{t}^{i}+K_{t}^{i} J\left(\frac{I_{t}^{i}}{K_{t}^{i}}\right)
$$

where $\delta$ is the rate of depreciation on capital and $K_{t}^{i} J\left(\frac{I_{t}^{i}}{K_{t}^{i}}\right)$ describes the cost of changing the capital stock. Following Hayashi (1982), the function $J($.$) is assumed to have the$ properties $J(\delta)=\delta, J^{\prime}(\delta)=1$, and $J^{\prime \prime}(\delta) \leq 0$. 
The household's utility-maximization problem yields Euler and labor supply equations that are similar to equations (8) and (9):

$$
\begin{aligned}
&\left(\frac{U_{C}^{\prime}\left(C_{t}^{i}, \frac{M_{t}^{i}}{P_{t}}\right)}{P_{t}}\right)=R_{t} \beta E_{t}\left[\left(\frac{U_{C}^{\prime}\left(C_{t+1}^{i}, \frac{M_{t+1}^{i}}{P_{t+1}}\right)}{P_{t+1}}\right)\right] \text { and } \\
& \widetilde{\omega}_{t}=\left(\frac{\sigma}{\sigma-1}\right) E_{t}\left[\frac{Y_{t} \eta\left(1-Y_{t}\left(\widetilde{\omega}_{t}\right)^{-\sigma}\right)^{-1}}{\left.Y_{t} U_{C}^{\prime}\left(C_{t}^{i}, \frac{M_{t}^{i}}{P_{t}}\right)+\beta Y_{t+1}\left(\frac{1}{\Pi_{t+1}}\right)^{1-\sigma} U_{C}^{\prime}\left(C_{t+1}^{i}, \frac{M_{t+1}^{i}}{P_{t+1}}\right)\right]}\right. \\
&+\left(\frac{\sigma}{\sigma-1}\right) E_{t}\left[\frac{\beta Y_{t+1}\left(\frac{1}{\Pi_{t+1}}\right)^{-\sigma} \eta\left(1-Y_{t+1}\left(\frac{\widetilde{\omega}_{t}}{\Pi_{t+1}}\right)^{-\sigma}\right)^{-1}}{Y_{t} U_{C}^{\prime}\left(C_{t}^{i}, \frac{M_{t}^{i}}{P_{t}}\right)+\beta Y_{t+1}\left(\frac{1}{\Pi_{t+1}}\right)^{1-\sigma} U_{C}^{\prime}\left(C_{t+1}^{i}, \frac{M_{t+1}^{i}}{P_{t+1}}\right)}\right]
\end{aligned}
$$

where:

$$
U_{C}^{\prime}\left(C_{t}^{i}, \frac{M_{t}^{i}}{P_{t}}\right)=\left(\frac{1}{C_{t}^{i}}\right) \frac{b\left(C_{t}^{i}\right)^{v}}{b\left(C_{t}^{i}\right)^{v}+(1-b)\left(\frac{M_{t}^{i}}{P_{t}}\right)^{v}}
$$

together with a money demand function:

$$
\frac{M_{t}^{i}}{P_{t}}=C_{t}^{i}\left(\left(\frac{b}{1-b}\right)\left(1-\frac{1}{R_{t}}\right)\right)^{\frac{-1}{1-\nu}}
$$

and a capital supply function:

$$
\begin{aligned}
& E_{t}\left[\frac{R_{t}}{\Pi_{t+1}} J^{-1^{\prime}}\left(\left(\frac{K_{t+1}^{i}}{K_{t}^{i}}\right)-(1-\delta)\right)\right] \\
= & E_{t}\left[\tilde{\rho}_{t+1}-J^{-1}\left(\left(\frac{K_{t+2}^{i}}{K_{t+1}^{i}}\right)-(1-\delta)\right)+\left(\frac{K_{t+2}^{i}}{K_{t+1}^{i}}\right) J^{-1^{\prime}}\left(\left(\frac{K_{t+2}^{i}}{K_{t+1}^{i}}\right)-(1-\delta)\right)\right] .
\end{aligned}
$$

The first-order conditions are log-linearized and calibrated with the same parameter values used by Huang and Liu (1998); details of these steps are given in the appendix.

Figure 1 displays the response of real output to a monetary shock implied by this model for the various values of $\sigma$ used by Huang and Liu (1998). ${ }^{13}$ As would be expected, the results - which show a persistent response of real output - are similar to those of Huang and Liu (1998). The degree of persistence increases with $\sigma$, since higher substitutability between labor inputs reduces the adjustment that households make to nominal wages.

\footnotetext{
${ }^{13}$ Since I am more interested in examining and comparing the persistence, rather than the absolute magnitude, of the responses, I rescale the response of output so that it equals one in the initial period. This allows me to determine quickly what fraction of the initial shock persists in any given period.
} 


\subsection{A Staggered Price Model}

The more detailed variant of the staggered price monetary business cycle model with firmspecific factor inputs broadly corresponds to the model presented in sections 2.3 and 2.4, but with capital introduced. The money growth process and market-clearing condition are still given by equations (19) and (20), while the utility function is given by equation (26) (but with $C_{t}^{i}$ now defined by equation (12)). With both factor inputs now firm-specific, household $i$ 's budget constraint changes so that the capital rental rate is indexed by household (that is $\left.\rho_{t}^{i}\right)$ in the same manner that the wage rate $\left(\omega_{t}^{i}\right)$ is indexed. Households' Euler equation and money demand equation are still given by (29) and (31), while the capital supply equation is modified to capture the firm-specific nature of capital (that is, the rental rate in equation (32) is now indexed by household). Since households no longer have market power over their labor, the first-order condition for hours supplied becomes:

$$
\frac{\omega_{t}^{j}}{P_{t}}=\frac{V^{\prime}\left(H_{t}^{j}\right)}{U_{C}^{\prime}\left(C_{t}^{i}, \frac{M_{t}^{i}}{P_{t}}\right)} .
$$

Firm $j$ now faces a production function with both firm-specific capital and labor inputs:

$$
Y_{t}^{j}=\left(H_{t}^{j}\right)^{1-\alpha}\left(K_{t}^{j}\right)^{\alpha}-F C
$$

which yields the following firm-specific factor demand function:

$$
\begin{aligned}
H_{t}^{j} & =\left(\frac{\alpha}{1-\alpha}\right)^{-\alpha} Y_{t}^{j}\left(\frac{\omega_{t}^{j}}{\frac{P_{t}}{\tilde{\rho}_{t}^{j}}}\right)^{-\alpha} \text { and } \\
K_{t}^{j} & =\left(\frac{\alpha}{1-\alpha}\right)^{1-\alpha} Y_{t}^{j}\left(\frac{\frac{\omega_{t}^{j}}{P_{t}}}{\widetilde{\rho}_{t}^{j}}\right)^{1-\alpha} .
\end{aligned}
$$

Firm $j$ 's price-setting problem is identical to that of section 2, implying a price-setting rule like equation (16). With two firm-specific factors of production, firm $j$ 's marginal cost becomes:

$$
\widetilde{M C}_{t}^{j}=\left(\widetilde{\rho}_{t}\right)^{1-\alpha}\left(\frac{\omega_{t}^{j}}{P_{t}}\right)^{\alpha} .
$$

The first-order conditions are log-linearized and calibrated as before (see the appendix). Figure 2 displays the response of output to a monetary shock in this model. To give some indication of the increased persistence brought about by the assumption of firm-specific factor inputs, I also present in Figure 2 the responses of real output from versions of this model with firm-specific labor and homogeneous capital, and with both homogeneous labor 
and capital. The increased persistence that obtains from assuming firm-specific factor inputs is evident from the figure.

\subsection{Discussion of the Quantitative Results}

The impulse-response functions presented in figures 1 and 2 confirm the analytical findings presented in the first part of the paper, namely, that a staggered price framework with firmspecific factor inputs is as capable as a staggered wage framework of producing persistent real responses to nominal shocks. The panels of figure 3 show (for various values of $\theta$ and $\sigma)$ that the response of real output emerging from the staggered wage model and staggered price model are essentially identical; this is the case also for the responses of consumption and investment (not shown). ${ }^{14}$ The assumption as to whether the assumed price stickiness is located in the model's factor or product market has a considerable influence on the resulting responses of inflation (not shown) and real wages (shown in figure 4 for various values of $\theta$ and $\sigma$ ). Most notably, the staggered pricing mechanism results in procyclical movements in the real wage, while the assumption of staggered wages generates countercyclical movements (for the values of $\sigma$ that generate greater degrees of persistence in real output).

\section{Conclusion}

This paper demonstrates that the conclusions of Andersen (1998) and Huang and Liu (1998) regarding the degree of persistence generated by staggered wage and staggered price models rely heavily on these authors' assumptions concerning factor market - specifically, that identical factor inputs are used by all firms. By assuming firm-specific factor inputs, this paper shows that a staggered price model is capable of generating responses to monetary shocks that are just as persistent as those that obtain from a staggered wage model. Moreover, the responses of real output and its components that obtain in the two models are essentially equivalent. These findings imply that monetary business cycle modelers need not rely on wage staggering to generate real and persistent responses to monetary shocks. The assumption of sticky prices (which is more easily justified than an assumption of sticky labor costs) is equally effective in generating intuitive responses to monetary shocks.

\footnotetext{
${ }^{14}$ Setting $F C=0$ in the staggered-price model with firm-specific inputs does not, however, yield identical responses in the two models as it did in section 3 (although it does yield more similar responses). Exact equivalence across the models in section 3 relied on the assumption of a single factor and linear specification of the production function.
} 


\section{References}

[1] Andersen, Torben M., "Persistency in Sticky Price Models," European Economic Review, 1998, 42, 593-603.

[2] Ascari, Guido, and Juan Angel Garcia, "Price/Wage Staggering and Persistence," Mimeo, 1999.

[3] Bergin, Paul R., and Robert C. Feenstra, "Staggered Price Setting and Endogenous Persistence," Journal of Monetary Economics, 2000, 45, 657-680.

[4] Blanchard, Olivier J., and C. M. Kahn, "The Solution of Linear Difference Models under Rational Expectations," Econometrica, 1980, 48, 1305-1311.

[5] Blanchard, Olivier J., "The Wage Price Spiral," Quarterly Journal of Economics, 1986, 101, 543-565.

[6] Chari, V. V., Patrick J. Kehoe, and Ellen R. McGratten, "Sticky Price Models of the Business Cycle: Can the Contract Multiplier Solve the Persistence Problem?" Federal Reserve Bank of Minneapolis Staff Report 217, 1998.

[7] Erceg, Christopher J., "Nominal Wage Rigidities and the Propagation of Monetary Disturbances," Federal Reserve Board International Finance Discussion Papers 590, 1997.

[8] Hayashi, Fumio, "Tobin's Marginal q and Average q: A Neoclassical Interpretation," Econometrica, 1982, 50, 213-24.

[9] Huang, Kevin X. D., and Zheng Liu, "Staggered Contracts and Business Cycle Persistence," Federal Reserve Bank of Minneapolis Discussion Paper 127, 1998.

[10] Katz, Lawrence F., and Kevin M. Murphy, "Changes in Relative Wages, 1963-1987: Supply and Demand Factors," Quarterly Journal of Economics, 1992, 107, 35-78

[11] Kiley, Michael T., "Staggered Price Setting and Real Rigidities," Federal Reserve Board Finance and Economics Discussion Series 46, 1997.

[12] Kim, Jinill, "Monetary Policy in a Stochastic Equilibrium Model with Real and Nominal Rigidities," Federal Reserve Board Finance and Economics Discussion Series 2, 1998

[13] Kimball, Miles S., "The Quantitative Analytics of the Basic Neomonetarist Model," Journal of Money, Credit, and Banking, 1995, 27, 1241-1277. 
[14] Koenig, Evan F., "Aggregate Price Adjustment: The Fisherian Alternative," Mimeo, 1997.

[15] Rotemberg, Julio J., "Prices, Output, and Hours: An Empirical Analysis Based on a Sticky Price Model," Journal of Monetary Economics, 1996, 37, 505-533.

[16] Taylor, John B., "Aggregate Dynamics and Staggered Contracts," Journal of Political Economy, 1980, 88, 1-23.

\section{A Appendix}

\section{A.1 Log-linearizing and Calibrating the More Detailed Staggered Wage Model}

The firm's first-order conditions, equations (22) to (25), log-linearize to:

$\widehat{H}_{t}^{i}=\widehat{Y}_{t}-\sigma \widehat{\widetilde{\omega}}_{t}+(\sigma-\alpha) \widehat{\widetilde{\Omega}}_{t}+\alpha \widehat{\widetilde{\rho}}_{t}$ where $i \in\{$ households who reset wages in period $t\}$ (38)

$\widehat{H}_{t}^{i}=\widehat{Y}_{t}+\sigma \widehat{\widetilde{\omega}}_{t}+(\sigma-\alpha) \widehat{\widetilde{\Omega}}_{t}+\alpha \widehat{\widetilde{\rho}}_{t}$ where $i \notin\{$ households who reset wages in period $t\}$ (39)

$$
\begin{gathered}
\widehat{K}_{t}=\widehat{Y}_{t}+(1-\alpha) \widehat{\widetilde{\Omega}}_{t}-(1-\alpha) \widehat{\widetilde{\rho}}_{t}, \\
\widehat{\widetilde{\Omega}}_{t}=\widehat{\widetilde{\omega}}_{t}+\widehat{\widetilde{\omega}}_{t-1}, \text { and } \\
(1-\alpha) \widehat{\widetilde{\Omega}}_{t}+\alpha \widehat{\widetilde{\rho}}_{t}=0 .
\end{gathered}
$$

The household's first-order conditions, ${ }^{15}$ equations (29) to (32), log-linearize to:

$$
\begin{aligned}
& \rho_{c c} \widehat{C}_{t}+\rho_{c m} \widehat{\widetilde{M}}_{t}=\widehat{R}_{t}+\rho_{c c} E_{t} \widehat{C}_{t+1}+\rho_{c m} \widehat{\widetilde{M}}_{t+1}-\widehat{\Pi}_{t+1}, \\
\widehat{\widetilde{\omega}}_{t}= & \left(\frac{\rho_{h h}}{1+\sigma \rho_{h h}}\right)\left(\left(\frac{1}{1+\beta}\right) \widehat{H}_{t}+\left(\frac{\beta}{1+\beta}\right) E_{t} \widehat{H}_{t+1}\right) \\
- & \left(\frac{\rho_{c c}}{1+\sigma \rho_{h h}}\right)\left(\left(\frac{1}{1+\beta}\right) \widehat{C}_{t}+\left(\frac{\beta}{1+\beta}\right) E_{t} \widehat{C}_{t+1}\right) \\
+ & \left(\frac{\sigma \rho_{h h}}{1+\sigma \rho_{h h}}\right)\left(\left(\frac{1}{1+\beta}\right) \widehat{\widetilde{\Omega}}_{t}+\left(\frac{\beta}{1+\beta}\right) E \widehat{\widetilde{\Omega}}_{t+1}\right)+\left(\frac{\beta}{1+\beta}\right) E \widehat{\Pi}_{t+1},
\end{aligned}
$$

\footnotetext{
${ }^{15}$ In what follows, a superscript asterisk $(*)$ on a variable denotes its level in the steady-state equilibrium.
} 


$$
\begin{gathered}
\widehat{\widetilde{M}}_{t}=\widehat{C}_{t}-\left(\frac{1}{1-\nu}\right)\left(\frac{1}{R^{*}}\right) \widehat{R}_{t}, \text { and } \\
\left\{\frac{1}{1+\delta \beta-\beta}\right\} \widehat{R}_{t}-\left\{\frac{1}{1+\delta \beta-\beta}\right\} \widehat{\Pi}_{t+1} \\
=E_{t} \widehat{\widetilde{\rho}}_{t+1}+\frac{J^{-1^{\prime \prime}}(\delta)}{1+\delta \beta-\beta}\left(\beta E_{t} \widehat{K}_{t+2}-(1+\beta) \widehat{K}_{t+1}+\widehat{K}_{t}\right),
\end{gathered}
$$

where

$$
\begin{gathered}
\rho_{h h}=\frac{H^{*}}{1-H^{*}}, \\
\rho_{c c}=\frac{\nu}{\left(\frac{b}{1-b}\right)\left(\frac{1-b}{b}\right)^{\frac{\nu}{\nu-1}}\left(\frac{R^{*}}{R^{*}-1}\right)^{\frac{\nu}{\nu-1}}+1}-1, \text { and } \\
\rho_{c m}=-\frac{\nu}{\left(\frac{b}{1-b}\right)\left(\frac{1-b}{b}\right)^{\frac{\nu}{\nu-1}}\left(\frac{R^{*}}{R^{*}-1}\right)^{\frac{\nu}{\nu-1}}+1} .
\end{gathered}
$$

The market-clearing condition together with the capital stock evolution equation (equations (20) and (28)) implies:

$$
\widehat{Y}_{t}=c \widehat{C}_{t}+(1-c)\left(\left(\frac{1}{\delta}\right) E_{t} \widehat{K}_{t+1}-\left(\frac{1-\delta}{\delta}\right) \widehat{K}_{t}\right)
$$

where $c$ (which equals $1-\frac{\delta \alpha}{\rho}$ ) denotes consumption's share of output in the steady state. The evolution of money growth is given by:

$$
\widehat{\mu}_{t}=\rho \widehat{\mu}_{t-1}+\varepsilon_{t} .
$$

I use the parameter values of Huang and Liu (1998) to calibrate the model; these values are summarized in the table below. The assumed length of a "period" is six months.

Table 1 - Calibrated Parameter Values

\begin{tabular}{|c|c|c|c|c|c|c|c|c|c|}
\hline Parameter: & $\alpha$ & $\delta$ & $\beta$ & $b$ & $\nu$ & $\rho$ & $J^{-1^{\prime \prime}}(\delta)$ & $H^{*}$ & $\Pi^{*}$ \\
\hline Value: & 0.33 & 0.0408 & 0.979 & 0.98 & -1.56 & 0.75 & 3.172 & 0.33 & 1 \\
\hline
\end{tabular}

Huang and Liu's (1998) assumed values for $\alpha, \delta$, and $\beta$ are standard. Values for $b$ and $\nu$ were obtained by fitting a regression for money demand (equation (31)), while $\rho$ was taken from a regression model of the money growth process (equation (19)). Huang and Liu (1998) chose $J^{-1^{\prime \prime}}(\delta)$ to match the observed volatility of investment relative to output. 
$H^{*}$ reflects the assumption that agents allocate one-third of their time to market activities while $\Pi^{*}$ is set equal to unity in order to simplify the problem. As $\beta=\frac{\Pi^{*}}{R^{*}}, \Pi^{*}=1$ implies that $R^{*}=\frac{1}{\beta}$. Huang and Liu (1998) cite a number of studies estimating the markup on wages and hence the parameter $\sigma .{ }^{16}$ These studies find a range of values for $\sigma$, so Huang and Liu experiment with four values of $\sigma(2,5,10$, and 20).

\section{A.2 Log-linearizing and Calibrating the More Detailed Staggered Price Model}

The firm's first-order conditions, equations (35) to (37) and (16), log-linearize to:

$\widehat{H}_{t}^{k}=\left(\frac{\theta-1}{\theta}\right) \widehat{Y}_{t}-(\theta-1) \widehat{\widetilde{x}}_{t}-\alpha \frac{\widehat{\omega_{t}^{k}}}{P_{t}}+\alpha \widehat{\widetilde{\rho}}_{t}^{k}$ where $k \in\{$ firms who reset prices in period $t\}$

$\widehat{H}_{t}^{l}=\left(\frac{\theta-1}{\theta}\right) \widehat{Y}_{t}+(\theta-1) \widehat{\widetilde{x}}_{t}-\alpha \frac{\widehat{\omega_{t}^{l}}}{P_{t}}+\alpha \widehat{\widetilde{\rho}}_{t}^{l}$ where $l \notin\{$ firms who reset prices in period $t\}$,

$$
\begin{aligned}
& \widehat{K}_{t}^{k}=\left(\frac{\theta-1}{\theta}\right) \widehat{Y}_{t}-(\theta-1) \widehat{\widetilde{x}}_{t}+(1-\alpha) \frac{\widehat{\omega_{t}^{k}}}{P_{t}}-(1-\alpha) \widehat{\widetilde{\rho}}_{t}^{k}, \\
& \widehat{K}_{t}^{l}=\left(\frac{\theta-1}{\theta}\right) \widehat{Y}_{t}+(\theta-1) \widehat{\widetilde{x}}_{t}+(1-\alpha) \frac{\widehat{\omega_{t}^{l}}}{P_{t}}-(1-\alpha) \widehat{\widetilde{\rho}}_{t}^{l}, \\
& \widehat{\widehat{M C}}_{t}^{k}=(1-\alpha) \frac{\widehat{\omega}_{t}^{k}}{P_{t}}+\alpha \widehat{\widetilde{\rho}}_{t}^{k} \\
& \widehat{\widetilde{M C}}_{t}^{l}=(1-\alpha) \frac{\widehat{\omega}_{t}^{l}}{P_{t}}+\alpha \widehat{\widetilde{\rho}}_{t}^{l}, \text { and } \\
& \widehat{\widetilde{x}}_{t}=\left(\frac{1}{1+\beta}\right) \widehat{\widetilde{M C}}_{t}^{k}+\left(\frac{\beta}{1+\beta}\right) E_{t} \widehat{\widetilde{M C}}_{t+1}^{l}+\left(\frac{\beta}{1+\beta}\right) E_{t} \widehat{\Pi}_{t+1},
\end{aligned}
$$

while the log-linearized equation for the evolution of prices is identical to that of section 2 , that is:

\footnotetext{
${ }^{16}$ Koenig (1997) estimates a value of $\sigma=20$ based on the average markup of union workers' wages over non-union workers' wages in the US during the period 1950 to 1980 . Kim (1998), who uses a maximumlikelihood method of estimation, finds a value of $\sigma=12$. Katz and Murphy (1992), who use more aggregated data, find even lower estimates of $\sigma$.
} 


$$
\widehat{\Pi}_{t}=\widehat{\widetilde{x}}_{t}+\widehat{\widetilde{x}}_{t-1}
$$

The household's log-linearized Euler equation and money demand equation in the stickyprice model are given by equations (43) and (45), while the log-linearized capital supply equation is similar to equation (46), but with capital and its rental rate indexed by household. Finally, equation (33) log-linearizes to:

$$
\widehat{\frac{\omega_{t}^{i}}{P_{t}}}=\rho_{h h} \widehat{H}_{t}^{i}-\rho_{c c} \widehat{C}_{t}-\rho_{c m} \widehat{M}_{t}
$$

while the market-clearing condition and evolution of money growth are identical to equations (47) and (48). The only new parameter in this model is $\theta$, which is in most cases set equal to 10 (this yields a value of 11 percent for firms' markup over marginal cost. 
Figure 3.1 - Impulse Responses of Output in the Staggered Wage Model

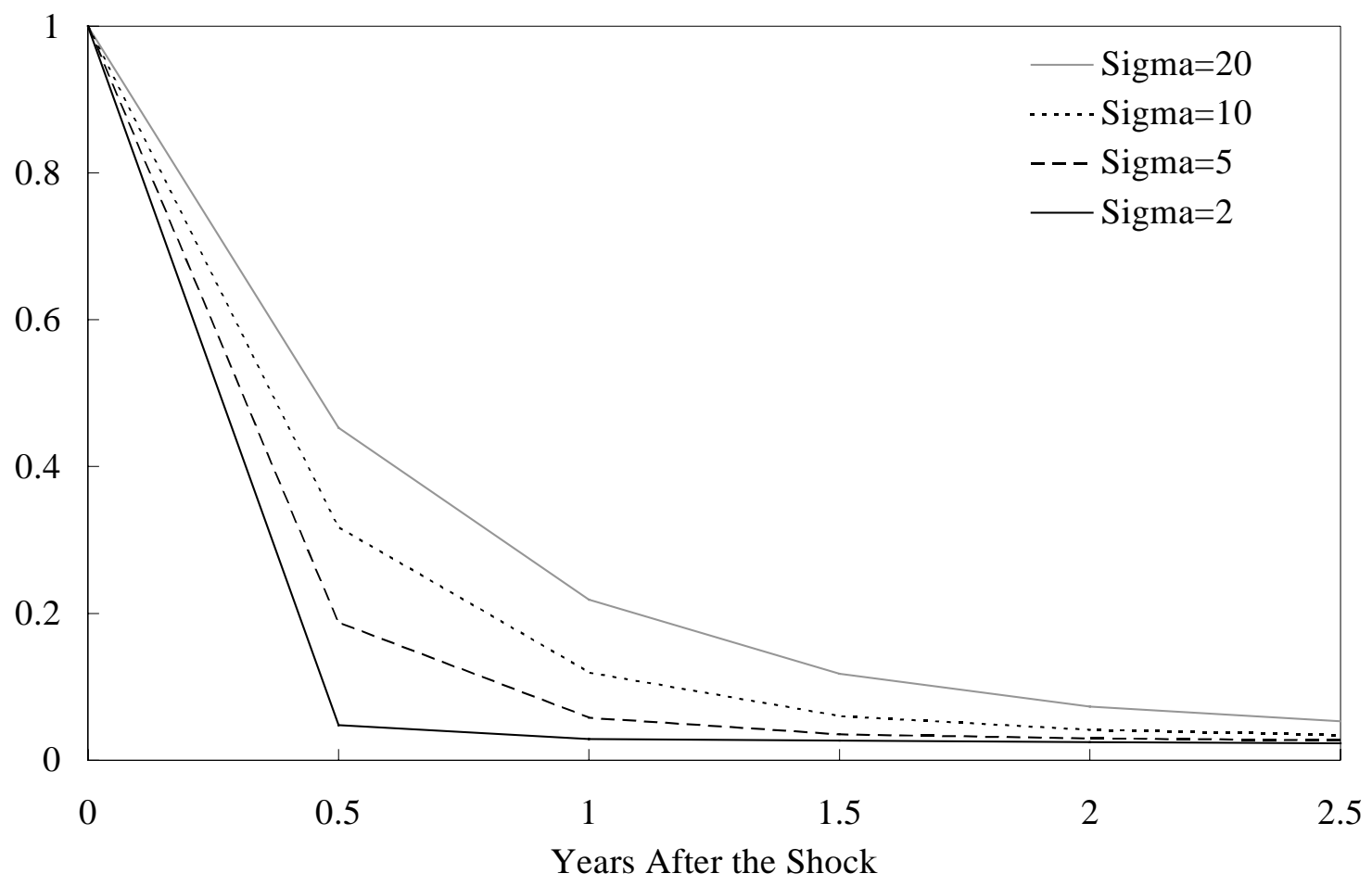

Figure 3.2 - Impulse Responses of Output in the Staggered Price Model for Theta $=10$

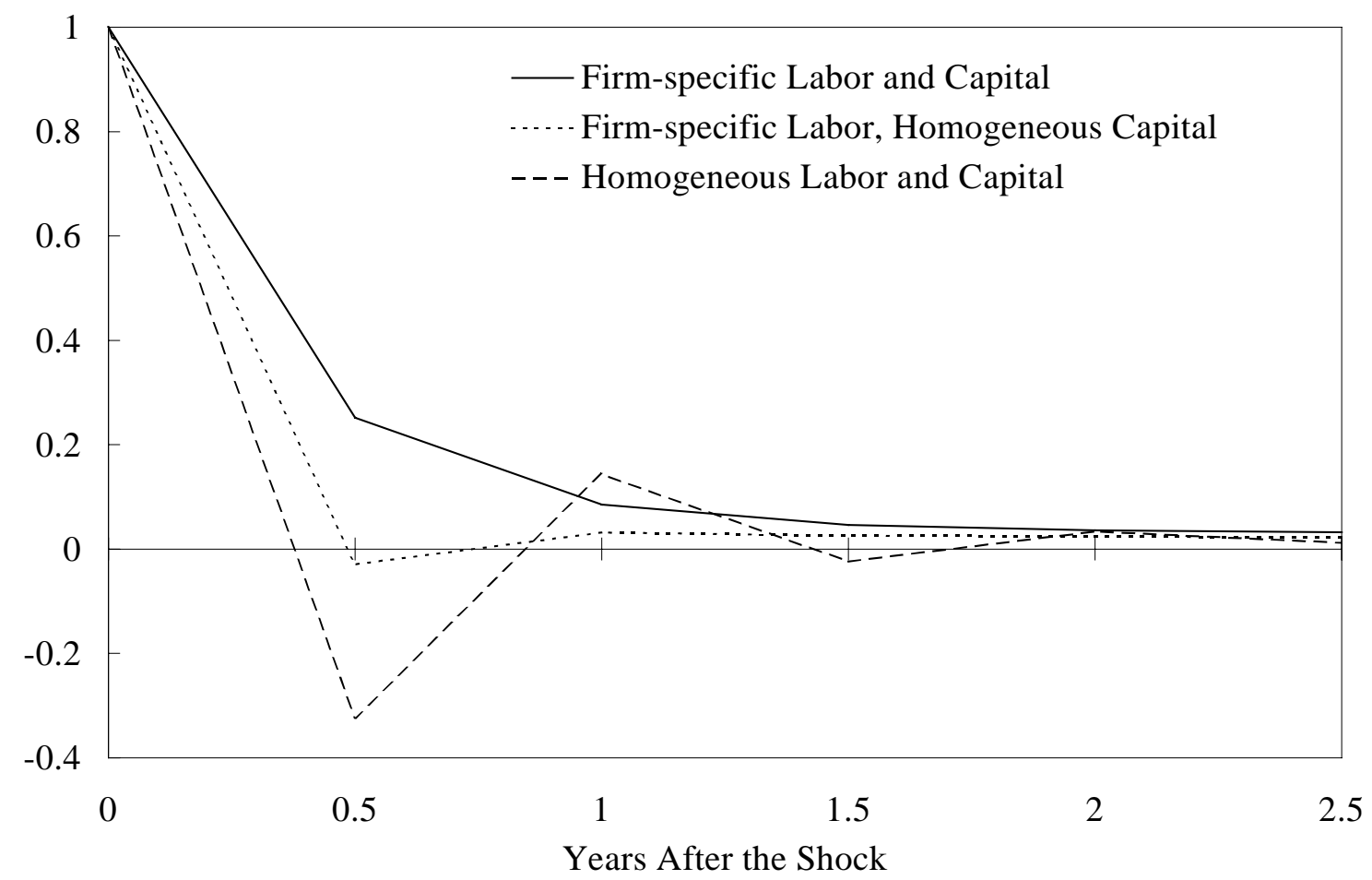


Figure 3.3 - Impulse Responses of Output in the Staggered Wage and Staggered Price Models for Various Values of $\sigma$ and $\theta$

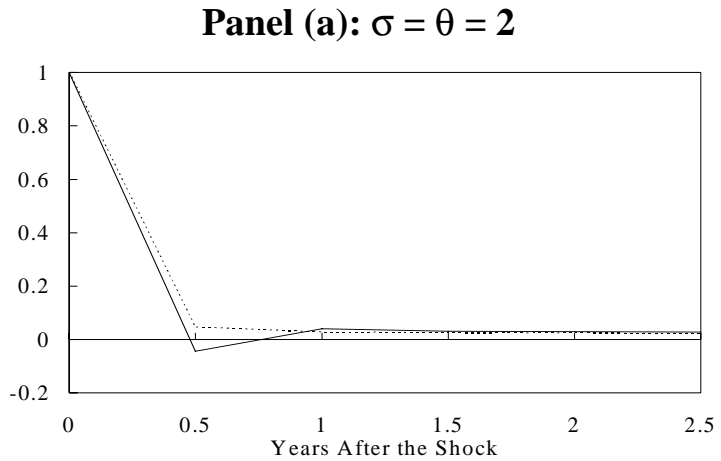

Panel (c): $\sigma=\theta=10$

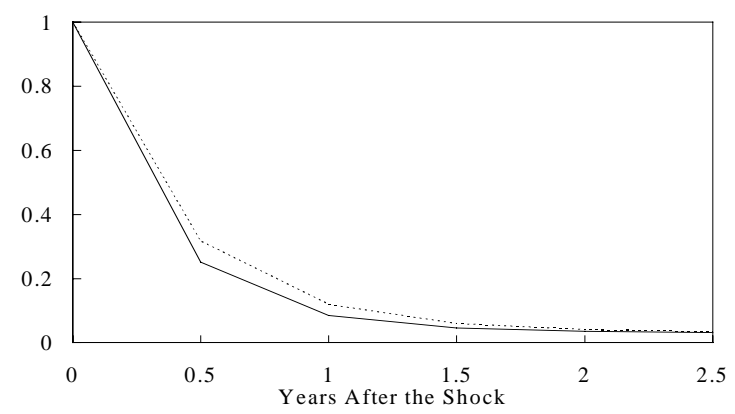

Panel (b): $\sigma=\theta=5$

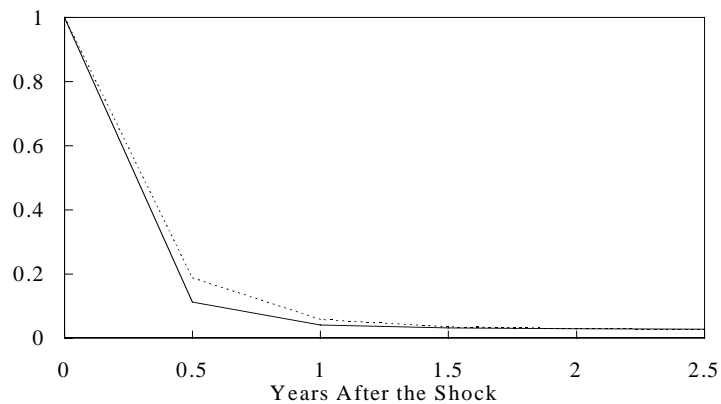

Panel (d): $\sigma=\theta=20$

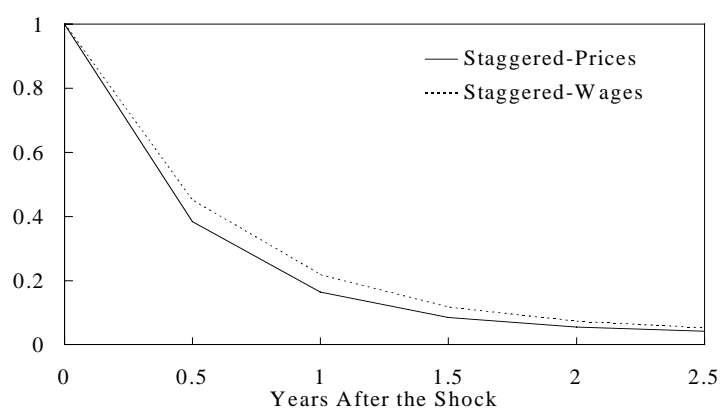

Figure 3.4 - Impulse Responses of the Real Wage in the Staggered Wage and Staggered Price Models for Various Values of $\sigma$ and $\theta$

Panel (a): $\sigma=\theta=2$

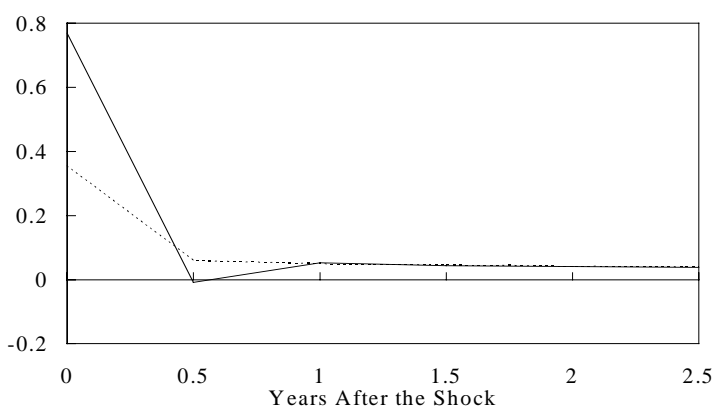

Panel (c): $\sigma=\theta=10$

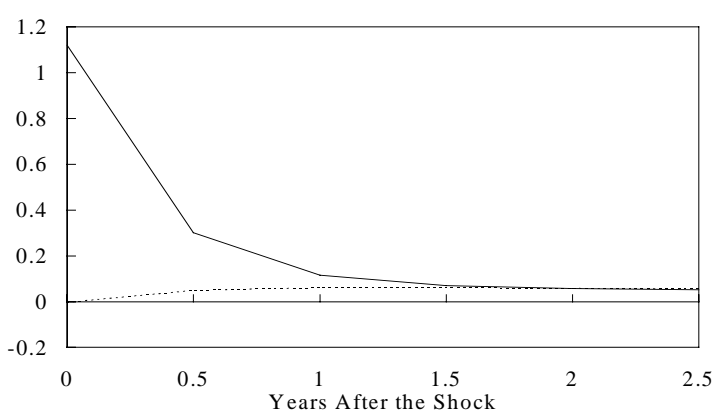

Panel (b): $\sigma=\theta=5$

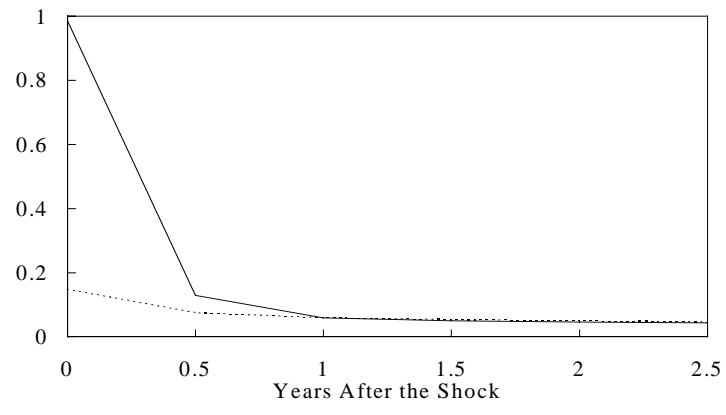

Panel (d): $\sigma=\theta=20$

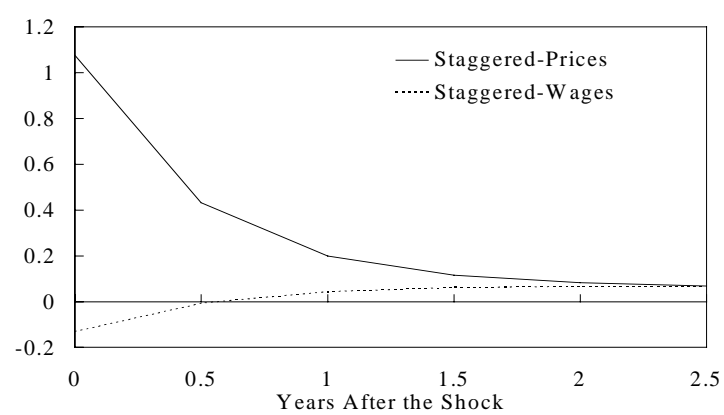

